\title{
Época de colheita e qualidade fisiológica de sementes de coentro produzidas no Norte de Minas Gerais
}

\author{
SOUSA, T.V. ${ }^{1 *}$; ALKIMIM, E.R. ${ }^{1}$; DAVID, A.M.S.S. ${ }^{2}$; SÁ, J.R. ${ }^{1}$; PEREIRA, G.A. ${ }^{1}$; AMARO, H.T.R. ${ }^{1}$; MOTA, W.F. ${ }^{2}$ \\ ${ }^{1}$ Acadêmicos do Curso de Agronomia da UNIMONTES - Dept ${ }^{\circ}$ de Ciências Agrárias, 39440-000, Janaúba-MG; \\ ${ }^{2}$ Professor do Departamento de Ciências Agrárias da UNIMONTES. *tiagronomia@yahoo.com.br
}

\begin{abstract}
RESUMO: No presente trabalho, objetivou-se avaliar a época de colheita e a qualidade fisiológica de sementes de coentro produzidas no Norte de Minas Gerais. A primeira época de colheita das sementes foi realizada aos 15 dias após o florescimento pleno, quando aproximadamente $50 \%$ das plantas apresentavam flores. As demais colheitas foram realizadas de $7 \mathrm{em} 7 \mathrm{dias}$, até as sementes atingirem $14,0 \%$ de umidade, fato que ocorreu na 6⿳亠丷厂 colheita. Imediatamente após cada colheita, as sementes foram avaliadas quanto ao teor de água, à germinação e ao vigor (testes de primeira contagem, emergência de plântulas e índice de velocidade de emergência). $A$ maturidade fisiológica das sementes de coentro, cultivar Verdão, ocorre entre 42 a 44 dias após o florescimento, quando as sementes apresentam umidade em torno de $28,0 \%$, podendo a colheita ser realizada até 50 dias após o florescimento, quando as sementes apresentavam 14,0\% de umidade.
\end{abstract}

Palavras-chave: Coriandrum sativum L., épocas de colheita, qualidade fisiológica.

\begin{abstract}
Harvest season and physiological quality of coriander seeds produced in the North of Minas Gerais. The present study aimed to evaluate the harvest season and physiological quality of coriander seeds produced in the North of Minas Gerais. The first season of harvest of the seeds was performed 15 days after full bloom, when approximately $50 \%$ of plants had flowers. The other crops were carried out 7 in 7 days, until the seeds reach $14,0 \%$ moisture, a fact that occurred in the 6th harvest. Immediately after each harvest, the seeds were evaluated for water content, germination and vigor tests (first count, seedling emergence and emergence speed index). The physiological maturity of coriander seeds, cultivate Verdão, occurs between 42 to 44 days after flowering, when the seeds had humidity around $28,0 \%$ at physiological maturity, the harvest may be held until 50 days after flowering, when seeds had $14,0 \%$ humidity.
\end{abstract}

Key words: Coriandrum sativum L., harvest season, physiological quality.

\section{INTRODUÇÃO}

O coentro (Coriandrum sativum L.), pertencente à família Apiaceae, é uma hortaliçacondimento de ciclo anual amplamente consumida no Brasil e, apesar de ser considerada uma "cultura de quintal", grande número de produtores está envolvido com sua exploração, tornando-a consequentemente uma cultura de grande importância socio-econômica.

De acordo com Oliveira et al. (2005) o coentro é cultivado por pequenos produtores, em hortas domésticas, escolares e comunitárias, e não objetiva apenas a produção da massa verde, comercializada em feiras livres e supermercados, mas também a produção de frutos, utilizados nas indústrias alimentícia e cosmética.

Suas sementes têm grande valor e importância comercial, por tratar-se de planta condimentar largamente utilizada no Brasil, com grande volume de importação e produção nacional de sementes. Em termos de volume de comercialização de sementes de hortaliças, o coentro equivale a 9\% do total. Em 2001, cerca de 270 toneladas de sementes desta espécie foram comercializadas no país, com valor aproximado de 2,7 milhões de reais Entretanto, estima-se que 25\% desse total comercializado sejam sementes importadas, principalmente dos EUA e Austrália. A produção nacional de sementes de coentro tem sido

Recebido para publicação: agosto de 2011

Aceito para publicação: dezembro de 2011

Rev. Bras. Pl. Med., Botucatu, v.13, especial, p.591-597, 2011. 
feita por diferentes empresas nos estados de RS, MG, PE e GO (Virgílio, 2001).

Poucas cultivares de coentro estão disponíveis aos produtores e, em algumas regiões, cultivam-se materiais locais, de procedência desconhecida, sendo as sementes produzidas pelos próprios agricultores, com um baixo nível tecnológico. Em geral, essas sementes apresentam baixa qualidade fisiológica. Vale ressaltar que entre as cultivares de coentro disponíveis no mercado, a cultivar Verdão é considerada líder em todo o Brasil, além de ser de ciclo precoce, em torno de 30 a 40 dias para a produção de folhas, dependendo da época do ano e da região. Esta cultivar é bastante vigorosa, com folhas de coloração verde-escura, excelente rusticidade e boa resistência às doenças de folhagens (Hortivale, 2011). Adicionalmente, Marques \& Lorencetti (1999) salientam que em cultivo solteiro, a cultivar Verdão apresenta melhor desempenho produtivo, quando comparado às cultivares Português e Palmeira.

Oliveira et al. (2007) relatam que apesar da existência, no mercado brasileiro, de cultivares de coentro de boa aceitação comercial, não há um programa regional de avaliação de genótipos visando identificar e recomendar aqueles melhor adaptados às diversas condições agroecológicas das zonas de cultivo.

Um aspecto importante na produção de sementes é a determinação da maturação fisiológica. Conhecer o processo de desenvolvimento e maturação das sementes objetiva não só definir o momento ideal de colheita, como também o estádio de máxima qualidade das mesmas que pode variar em função da espécie e das condições de ambiente. Desta forma, é importante estabelecer características da planta e/ ou sementes que permitam a correta definição da época de colheita, pois a permanência das sementes no campo após a maturidade fisiológica pode ser associada a perdas na produtividade, germinação e no vigor. O acompanhamento do desenvolvimento das sementes durante o processo de maturação é feito com base nas modificações que ocorrem em algumas características de natureza física e fisiológica, como tamanho, teor de água, conteúdo de matéria seca, germinação e vigor, como relatado por Dias (2001).

O processo de maturação das sementes, definida por Hartmann et al. (1997), compreende as mudanças morfológicas e fisiológicas que ocorrem entre a fertilização e o momento em que as sementes, tornando-se independentes da planta-mãe, apresentam o máximo potencial fisiológico.

Deve-se, entretanto, alertar que o ponto de maturidade fisiológica, dentro de cada espécie, pode variar em relação ao momento de sua ocorrência, em função da cultivar estudada e do local de cultivo. Nesse sentido, Popinigis (1996) enfatiza que a obtenção de sementes de alta qualidade fisiológica é dificultada em espécies caracterizadas pela desuniformidade na maturação. Nesse contexto, Bezerra et al. (1995) verificaram, na cultura do coentro, que as umbelas nos estádios de antese, verdes, maduras e secas ocorrem, respectivamente, nos intervalos de 55-75; 55-80; 70-95 e 85-100 dias após a emergência, tendo sido observado aos 95 dias valores máximos para germinação e acúmulo de matéria seca nas sementes.

Apesar do prognóstico favorável sobre a cultura do coentro no Brasil, não foram encontrados trabalhos relacionados com o processo de maturação de sementes, indicando a necessidade de pesquisa.

Dessa forma, no presente trabalho objetivouse avaliar a época de colheita e a qualidade fisiológica de sementes de coentro produzidas no Norte de Minas Gerais.

\section{MATERIAL E MÉTODO}

O campo de produção de sementes foi instalado no Horto de Plantas Medicinais, e as análises laboratoriais foram realizadas no laboratório de Análise de sementes do Departamento de Ciências Agrárias (DCA), da Universidade Estadual de Montes Claros (Unimontes), na cidade de Janaúba, norte de Minas Gerais. Foram utilizadas sementes de coentro da cultivar Verdão, sendo o plantio realizado em 16 de abril de 2010.

O município de Janaúba localiza-se na

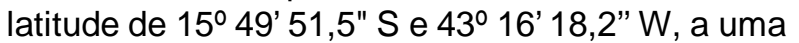
altitude de 540 metros. A pluviosidade média da região é de aproximadamente 870 mm e insolação de 2.700 horas anuais. O clima da região de é classificado por Koeppen (1948) como "AW", tropical com inverno seco.

$\mathrm{Na}$ área onde o experimento foi conduzido, foram coletadas amostras de solo com um auxílio de um trado na profundidade de 0 a $20 \mathrm{~cm}$, as quais posteriormente foram analisadas. A interpretação e recomendação das adubações de plantio e cobertura foram realizadas de acordo com 0 manual da $5^{\underline{a}}$ aproximação (Ribeiro et al., 1999).

Durante o preparo dos canteiros foram adicionados ao solo $6 \mathrm{~kg} \cdot \mathrm{m}^{-2}$ de esterco bovino e realizada uma adubação química contendo $46,8 \mathrm{~g} \cdot \mathrm{m}^{-}$ ${ }^{2}$ de Super Fosfato Simples (140 kg.ha-1 de $\mathrm{P}_{2} \mathrm{O}_{5}$ ), $7,02 \mathrm{~g} \cdot \mathrm{m}^{-2}$ de $\mathrm{KCl}\left(70 \mathrm{~kg} \cdot \mathrm{ha}^{-1} \mathrm{~K}_{2} \mathrm{O}\right.$ ) e $5,4 \mathrm{~g} \cdot \mathrm{m}^{-2} \mathrm{de}$ Uréia (40 kg.ha-1 de N) com distribuição a lanço. Aos 20 dias, após a emergência, foi realizada uma adubação de cobertura contendo $4 \mathrm{~g} \cdot \mathrm{m}^{-2}$ de $\mathrm{N}$ e 7 g. $\mathrm{m}^{-2}$ de $\mathrm{K}_{2} \mathrm{O}$.

Após a abertura de sulcos, utilizou-se espaçamento de $10,0 \mathrm{~cm}$ entre linhas, sendo as sementes semeadas a uma profundidade de aproximadamente $3,0 \mathrm{~cm}$. Após a emergência,

Rev. Bras. Pl. Med., Botucatu, v.13, especial, p.591-597, 2011. 
realizou-se o desbaste deixando uma planta a cada $8,0 \mathrm{~cm}$. Utilizaram-se dez linhas, desprezando-se as plantas nas linhas de bordadura. Durante a condução do experimento foram realizadas capinas manual e irrigação com sistema de micro-aspersão. Não se realizou controle fitossanitário devido à ausência de pragas e doenças.

O delineamento experimental utilizado foi inteiramente casualizado (DIC), composto por seis épocas de colheitas, que consistiram nos tratamentos, e quatro repetições por tratamento.

A primeira época de colheita das sementes foi realizada aos 15 dias após o florescimento pleno, quando aproximadamente $50 \%$ das plantas apresentavam flores, ocorrendo em 19 de julho de 2010. As demais colheitas foram realizadas em intervalos de sete em sete dias, até as sementes atingirem, em torno de $14,0 \%$ de umidade.

A colheita das umbelas foi realizada aleatoriamente sendo retirada uma amostra representativa em todas as linhas de plantio, de forma que a quantidade de sementes atendesse a demanda das análises realizadas posteriormente. Depois da colhidas, as umbelas foram transportadas até 0 laboratório, embaladas em sacos de plástico, que foram vedados, sendo em seguida processadas manualmente para a retirada das sementes.

O teor de água das sementes foi determinado conforme metodologia prescrita nas Regras para Análise de Sementes (Brasil, 2009), utilizando o método da estufa, a $105 \pm 3^{\circ} \mathrm{C}$, durante 24 horas, com quatro subamostras de 10 gramas de sementes, para cada repetição, sendo os resultados expressos em \% de teor de água.

Para a realização do teste de germinação utilizou-se caixas plásticas tipo gerbox, onde as sementes foram distribuídas sobre uma folha de papel mata-borrão, previamente umedecida com água destilada, em volume equivalente a 2,5 vezes o peso do papel seco. As caixas contendo as sementes foram colocadas em germinador previamente regulado à temperatura constante de $20^{\circ} \mathrm{C}$. As avaliações foram realizadas no sétimo e vigésimo primeiro dias após a semeadura, e os resultados expressos em porcentagem de plântulas normais, conforme recomendação da RAS - Regra de Análises de Sementes (Brasil, 2009).

Os resultados do teste de primeira contagem foram obtidos pelo número de plântulas normais, determinado por ocasião da primeira contagem do teste de germinação, ou seja, sétimo dia após a montagem (Brasil, 2009).

O teste de emergência de plântulas foi conduzido sob condições não controladas de laboratório, utilizando areia anteriormente lavada e esterilizada em estufa a $200^{\circ} \mathrm{C}$, durante duas horas. As sementes foram semeadas em caixas plásticas tipo gerbox com $3 \mathrm{~cm}$ de profundidade e o teor de água foi mantido com irrigações leves diariamente (Brasil, 2009). Utilizaram-se quatro repetições de 50 sementes por tratamento e os resultados foram obtidos pelo número de plântulas normais emergidas, determinado por ocasião do vigésimo primeiro dia após a semeadura.

O índice de velocidade de emergência foi conduzido em conjunto com o teste de emergência de plântulas, anotando-se diariamente, no mesmo horário, o número de plântulas que apresentavam dois $\mathrm{cm}$ de altura. Ao final do teste, com os dados diários do número de plântulas emergidas, foi calculado o índice de velocidade de emergência, empregando-se a fórmula proposta por Maguire (1962).

As variáveis estudadas foram analisadas utilizando-se o programa de análises estatísticas Sisvar 5.3 (Ferreira, 2010), desenvolvido pela Universidade Federal de Lavras-UFLA. Os resultados foram submetidos à análise de variância e regressão em nível de 5\% pelo teste "F". As estimativas dos parâmetros da regressão foram avaliadas pelo teste "t" em nível de $5 \%$ de significância.

\section{RESULTADO E DISCUSSÃO}

Na Figura 1 são apresentados os teores de água, em porcentagem, das sementes de coentro, cultivar Verdão, em função da época de colheita. $O$ teor de água das sementes que, inicialmente, aos 15 dias após a floração, era de $83,0 \%$, caiu acentuadamente, até atingir $28,0 \%$ aos 42 dias após a floração, período em que ocorreu a maturidade fisiológica das sementes. Esse decréscimo observado foi contínuo durante todo o período analisado, sendo que aos 50 dias após o florescimento (sexta época colheita) o teor de água das sementes era de aproximadamente 14,0\%. Entretanto, Hunter et al. (1991), argumentaram que embora seja amplamente utilizado, o teor de água das sementes não é um bom indicador de maturidade fisiológica por sofrer influências ambientais e genéticas.

Vale ressaltar que o teor de água observado nas sementes, por ocasião da sexta colheita, foi relativamente baixo fato que segundo Pedroso (2008), permite uma maior confiabilidade aos resultados obtidos nas análises realizadas. Em adição, Coimbra et al. (2009) salientam que o teor de água reduzido é imprescindível para a obtenção de resultados consistentes na avaliação da qualidade fisiológica de sementes.

Observou-se que a redução na umidade ocorreu de forma linear, sendo que a cada dia a semente perdia 1,95\% do seu teor água.

Na Figura 2 constam os resultados médios de germinação das sementes de coentro da cultivar Verdão, em função das épocas de colheita. Observa-

Rev. Bras. PI. Med., Botucatu, v.13, especial, p.591-597, 2011. 


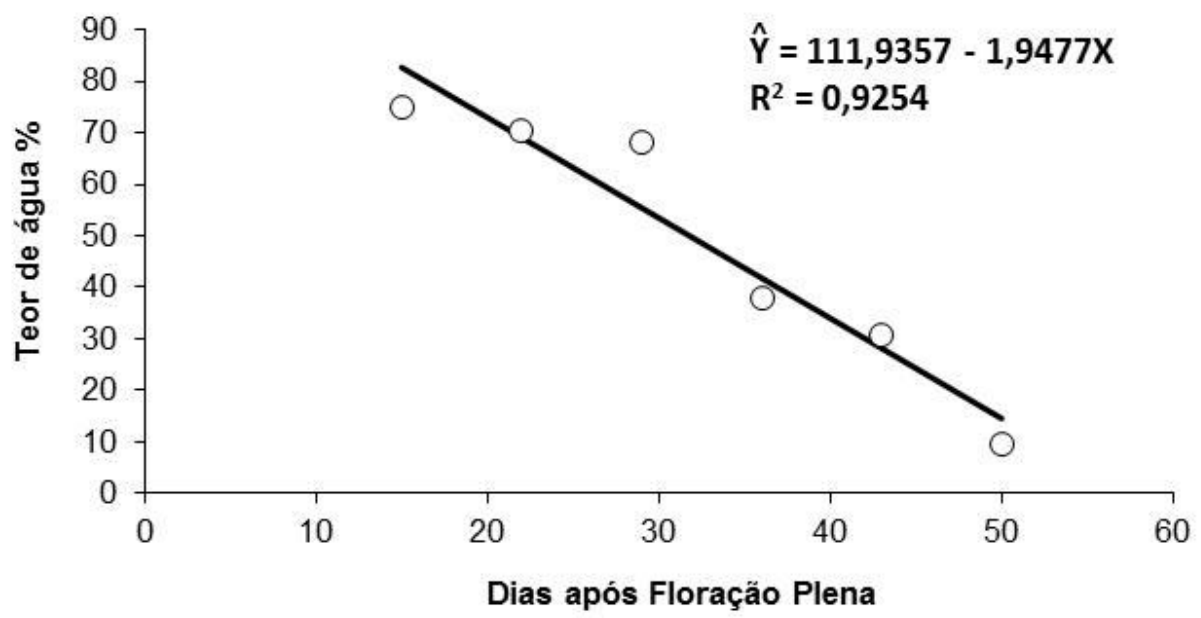

FIGURA 1. Teor de água (\%) de sementes de coentro, cultivar Verdão, em função da época de colheita.

se que as sementes apresentavam aproximadamente $16 \%$ de germinação na primeira época de colheita (15 dias após a floração), atingindo 88\% (42 dias após a floração) próximo da quinta colheita (43 dias após a floração). Esses valores demonstram que houve incrementos de $450 \%$ na porcentagem de germinação da primeira colheita até o ponto de máximo (42 dias após a floração), período em que ocorreu a máxima porcentagem de germinação das sementes. Entretanto nessa época em que foram observados maiores percentuais de germinação, as sementes encontravam-se com elevado teor de água ( $28 \%$ ), fato este que é considerado empecilho para a colheita mecanizada dessa cultura. Dessa forma é interessante que a colheita seja retardada para a sexta época (50 dias após a floração), haja visto que nesse período, as sementes apresentavam-se com teor de água reduzido, em torno de 14,0\%.

Pelos padrões nacionais para produção e comercialização de sementes de coentro, a porcentagem de germinação mínima deve ser de $65 \%$ para sementes básicas e de $70 \%$ para as certificadas de primeira e de segunda geração e para as sementes S1 e S2 (MAPA, 2011). Verificou-se que da terceira época de colheita em diante, todos esses níveis foram superados.

Deve-se ressaltar que a alta porcentagem de germinação das sementes nas primeiras colheitas, embora ainda se encontrem com elevado teor de água, pode ser de grande utilidade para acelerar os programas de melhoramento, obtendo deste modo, mais de uma geração por ano. Adicionalmente, observou-se no presente trabalho que as sementes colhidas com altos teores de água, após a secagem natural apresentaram valores de germinação semelhantes aos das sementes colhidas com menores teores de água.

A partir da quinta colheita, no entanto, constatou-se uma queda na porcentagem de germinação das sementes, que não afetou consideravelmente sua qualidade, já que a germinação permaneceu acima de $80 \%$. Tal fato demonstra que possivelmente a ocorrência de estresses ambientais como elevadas temperaturas e umidade relativa do ar, reduziu a capacidade da planta de produzir assimilados para as sementes.

Verdelho \& Assunção (1997) ressaltam que somente os resultados de germinação em sementes de agrião-do-brejo (Eclipta alba) não constitui um indicador seguro para determinação da época ideal de colheita desta espécie, pois, o fato de se obter altos índices germinativos não implicou, necessariamente, em dizer que as sementes eram vigorosas.

Observando-se os resultados de vigor, avaliado pelo teste de primeira contagem, verifica-se valores poucos expressivos na porcentagem de plântulas normais por ocasião da primeira colheita (15 dias após a floração) (Figura 3). A partir dessa época, no entanto, estes valores aumentaram acentuadamente, até atingir aproximadamente $79 \%$ aos 43 dias após a floração (5a época de colheita), período em que as sementes apresentavam máximo vigor, coincidindo com o período de máxima germinação.

A partir dos 43 dias após a floração, o vigor decresceu, provavelmente devido a deterioração no campo, em decorrência do atraso na colheita. Os resultados indicaram que a queda no vigor detectada pelo teste de primeira contagem foi mais acentuado que a redução na germinação à medida que se retardava a colheita, no entanto, vale salientar que essas reduções não foram tão expressivas a pontos de inviabilizar o atraso na colheita das sementes.

O vigor das sementes, com base nos resultados do teste de emergência de plântulas (Figura 4), evidenciaram que, na primeira época de colheita (15 dias após a floração), as sementes apresentavam- 


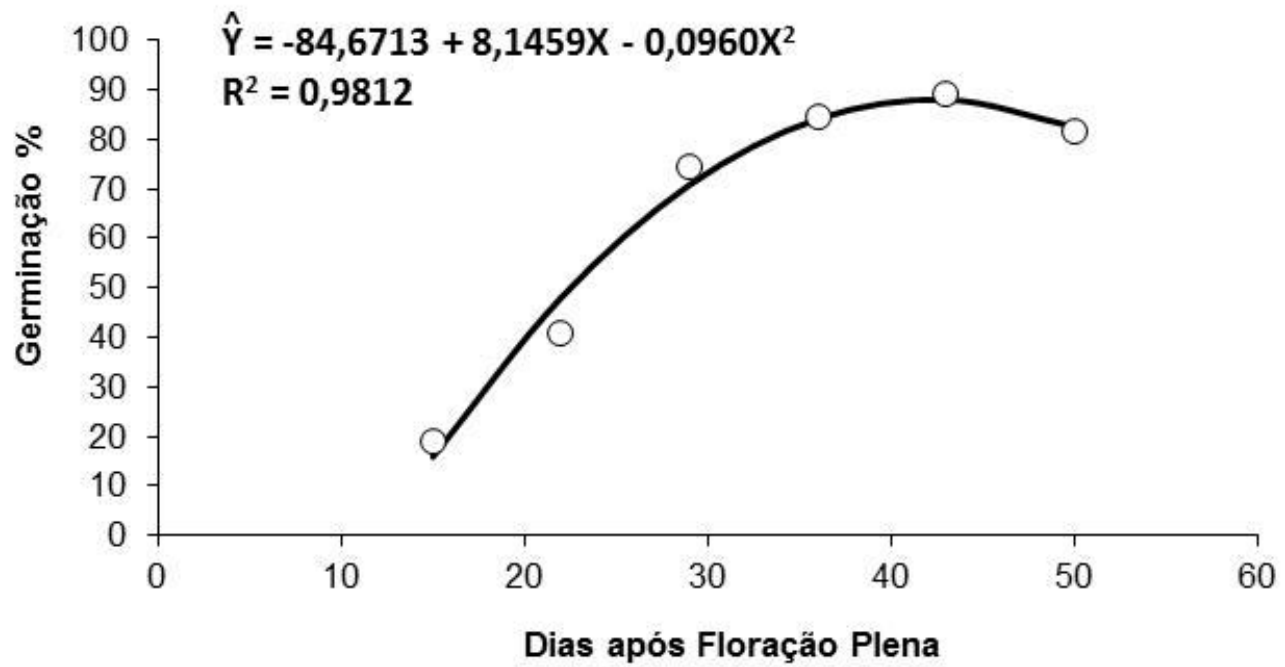

FIGURA2. Resultados médios em porcentagem do teste de germinação de sementes de coentro, cultivar Verdão, em função da época de colheita.

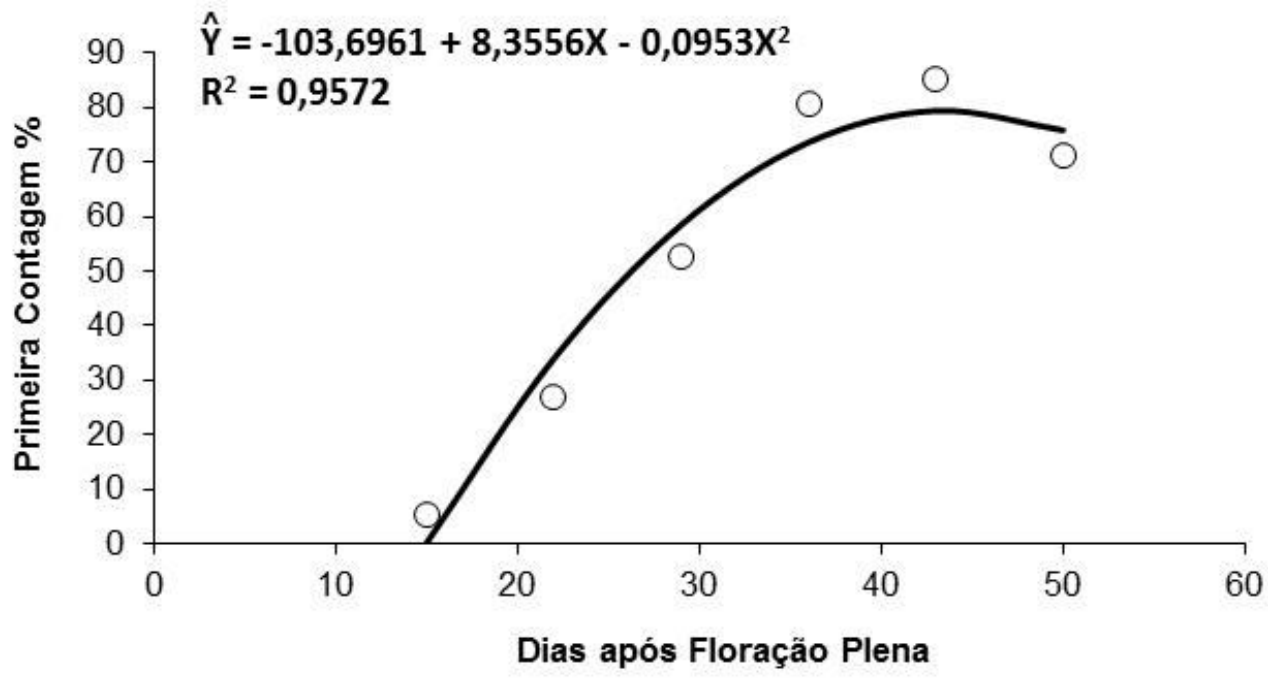

FIGURA 3. Resultados médios em porcentagem do teste de primeira contagem de germinação de sementes de coentro, cultivar Verdão, em função da época de colheita.

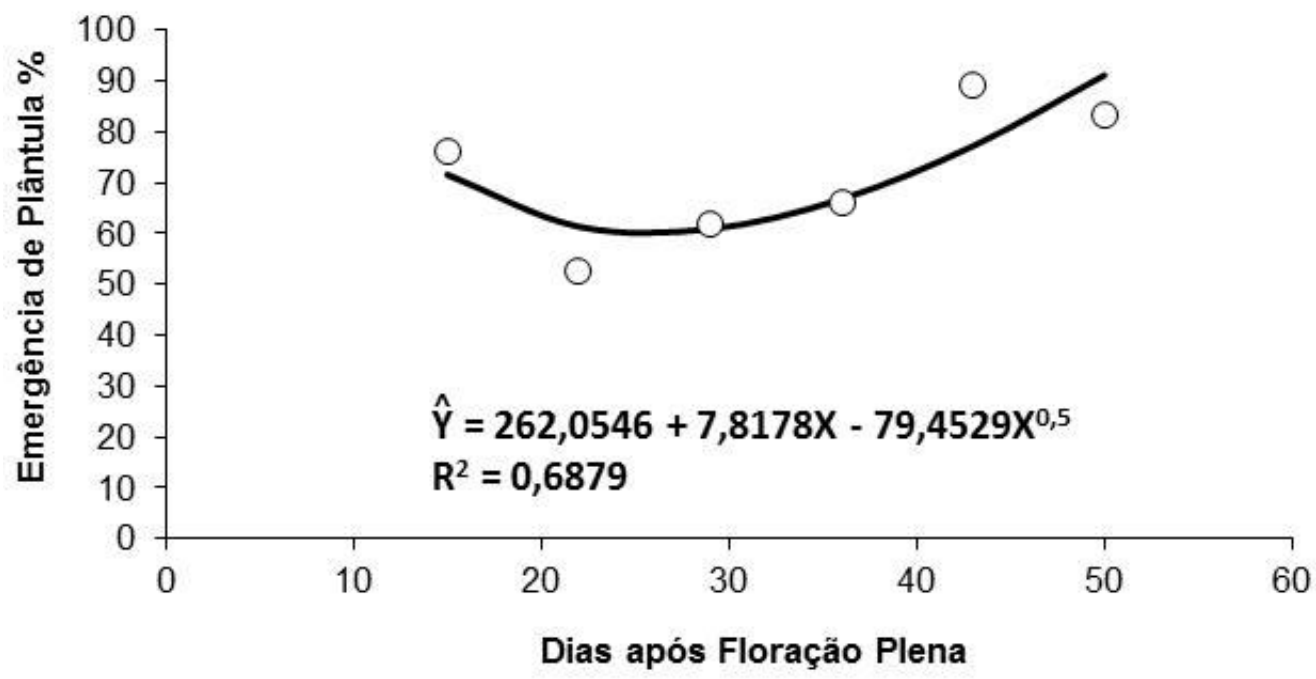

FIGURA 4. Resultados médios de emergência de plântulas de sementes de coentro, cultivar Verdão, em função da época de colheita. 


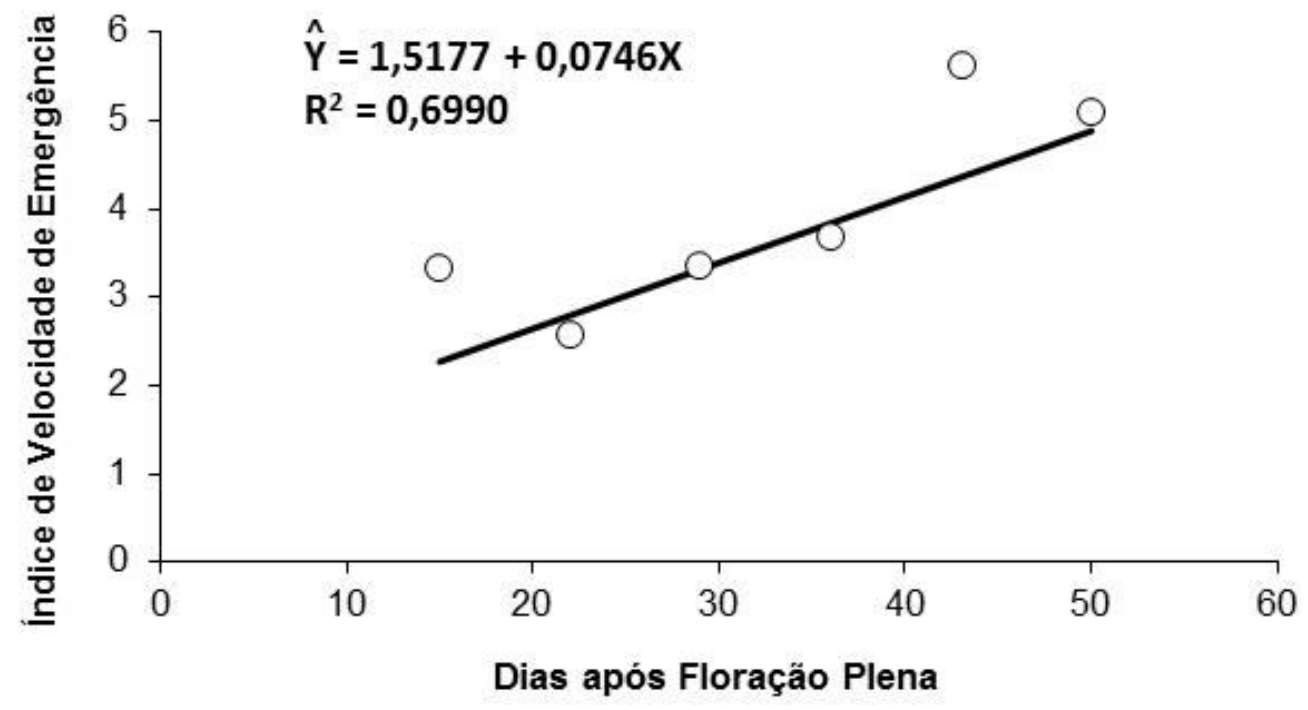

FIGURA 5. Resultados médios de índice de velocidade de emergência de sementes de coentro, cultivar Verdão, em função da época de colheita.

se vigorosas. No entanto, verificou-se que a partir desse período, houve decréscimos na porcentagem de plântulas normais. Esse resultado, possivelmente, foi devido ao maior número de sementes ainda não totalmente formadas em função da desuniformidade verificada na maturação das umbelas, como relatado por Bezerra et al. (1995), bem como algum tipo de dormência devido a imaturidade do embrião. Vale ressaltar que as condições de estresses ambientais como elevadas temperaturas e umidade relativa do ar observadas durante o período, também podem ter favorecido para a redução no vigor das sementes. A partir desse ponto os resultados foram se elevando, e aos 50 dias após a floração (6 ${ }^{a}$ colheita), as sementes apresentaram-se com seu máximo vigor.

Por meio do teste índice de velocidade de emergência (Figura 5) verificou-se que as sementes apresentaram valores máximos por ocasião da sexta época de colheita (50 dias após o florescimento), sendo obtidos valores de aproximadamente 4,9. Aos 43 dias após a floração (5a época de colheita) os índices verificados, foram de 4,4.

Observou-se que os resultados do índice de velocidade de emergência apresentaram crescimento linear, ocorrendo incremento de 0,075 nos índices verificados a cada dia.

Em geral, pode-se observar que a qualidade fisiológica das sementes colhidas aos 50 dias, com aproximadamente $14,0 \%$ de umidade, praticamente não foi afetada.

A maturidade fisiológica das sementes de coentro da cultivar Verdão ocorre entre 42 a 44 dias após o florescimento, quando as sementes apresentam umidade em torno de $28,0 \%$. No entanto, a colheita das sementes pode ser realizada até 50 dias após o florescimento, quando as sementes apresentavam $14,0 \%$ de umidade, e uma boa qualidade fisiológica.

\section{AGRADECIMENTO}

A Universidade Estadual de Montes Claros - Unimontes, pelo suporte técnico nesta pesquisa e à Fundação de Amparo à Pesquisa do Estado de Minas Gerais (FAPEMIG) pelo apoio financeiro.

\section{REFERÊNCIA}

BEZERRA, A.M.E.; CHAVES, F.C.M.; ASSUNÇÃO, M.V. Produtividade e qualidade das sementes de coentro provenientes de diferentes colheitas. In: REUNIÃO DE PESQUISA DO CENTRO DE CIÊNCIAS AGRÁRIAS, 4., 1995, Teresina. Anais... Teresina: UFPI, 1995. p.116-122. BRASIL. Ministério da Agricultura, Pecuária e Abastecimento. Regras para análise de sementes. Brasília: SNAD/DNDV/CLAV, 2009. 365p.

COIMBRA, R.A.; MARTINS, C.C.; TOMAZ, C.A.; NAKAGAWA, J. Testes de vigor utilizados na avaliação da qualidade fisiológica de sementes de milho-doce (sh2). Ciência Rural, v.39, n.9, p.2402-2408, 2009.

DIAS, D.C.F. Maturação de sementes. SEED News, v.5, n.6, 2001. Disponível em: http://www.seednews.inf.br/ portugues/seed56/artigocapa56.shtml. Acesso em: 15 Mar. 2011.

FERREIRA, D.F. SISVAR - Sistema de análise de variância. Versão 5.3. Lavras-MG: UFLA, 2010.

HARTMANN, H.T.; KESTER, D.E.; DAVIES Jr., F.T.; GENEVE, R.L. Plant propagation: principles and 
practices. 6.ed. New Jersey: Prentice Hall International, 1997. 770p.

HORTIVALE. Hortivale - Sementes do Vale Ltda. 2011. Disponível em <http://www.hortivale.com.br>. Acesso em: 15 Mar. 2011.

HUNTER, J.L.; TEKRONY, D.M.; MILES, D.F.; EGLI, D.B. Corn seed maturity indicators and their relationship to uptake of Carbon-14 assimilate. Crop Science, v.31, n.5, p.1309 - 1313, 1991.

KÖEPPEN, W. Climatologia: con um estúdio de los climas de la Tierra. México: Fondo de Cultura Economica, 1948. 478p.

MAGUIRE, J.D. Speed of germination - aid in selection and evaluation for seedling emergence and vigor. Crop Science, 2(2):176-177, 1962.

MARQUES, F.C.; LORENCETTI, B.L. Avaliação de três cultivares de coentro (Coriandrum sativum L.) semeadas em duas épocas. Pesquisa Agropecuária Gaúcha, v.5, n.2, p.265-270, 1999.

MINISTÉRIO DA AGRICULTURA, PECUÁRIA E ABASTECIMENTO - MAPA, SECRETARIA DE DEFESA AGROPECUÁRIA, Portaria SDA n 51, de 2 de março de 2011.

OLIVEIRA, A.P de. et al. Desempenho de genótipos de coentro em Areia. Horticultura Brasileira, v.25, n.2, p.252255, 2007.

OLIVEIRA, E.Q.; BEZERRA NETO, F.; NEGREIOS, M.Z.;
BARROS JUNIOR, A.P.; FREITAS, K.K.C.; SILVEIRA, L.M.; LIMA, J.S.S. Produção e valor agroeconômico no consórcio entre cultivares de coentro e de alface. Horticultura Brasileira, v.23, n.2, p.285-289, 2005. PEDROSO, D.C. Associação de Alternaria spp. com sementes de apiáceas: métodos de inoculação e influência na qualidade fisiológica. 2008. $118 \mathrm{f}$. Dissertação (Mestrado - Área de Concentração em Produção Vegetal). Centro de Ciências Rurais, Universidade Federal de Santa Maria, Santa Maria - RS. POPINIGIS, F. Fatores que afetam a qualidade das sementes. In: PUIGNAU, J.P. Conservación de germoplasma vegetal. Montevideo: IICAPROCISUR, 1996. p.93-98.

RIBEIRO, A.C.; GUIMARÃES, P.T.G.; ALVAREZ, V.V.H. Recomendações para o uso de corretivos e fertilizantes em Minas Gerais - 5a Aproximação. Comissão de Fertilidade do Solo do Estado de Minas Gerais-CFSEMG, Viçosa, MG, 1999.359p.

VALENTINI, S.R.T.; PIÑA-RODRIGUES, F.C. Aplicação do teste de vigor em sementes. São Paulo: [s.n.], 1995. p.75-84 (IF Série Registro, 14).

VERDELHO, M.M.D.A.R.; ASSUNÇÃO, M.V.A. Maturação de sementes de agrião-do-brejo. Horticultura Brasileira, v.15, n.1, p.62-64, 1997.

VIRGílIO, I.G.F. Sementes da mudança. Agroanalysis, p.13-15, agosto, 2001. 